\title{
2019 Annual Trends and Outlook Report Gender Equality in Rural Africa: From Commitments to Outcomes
}

November 2019

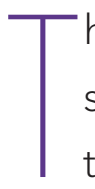
he Malabo Declaration of 2014 outlines seven commitments to enhance livelihoods through inclusive agricultural growth in Africa. Ending hunger, reducing poverty, boosting intra-African trade, and increasing resilience to climate and other risks will require examining how gender differences affect our ability to achieve these outcomes. Gender-sensitive policy and programming have an integral role to play in fostering inclusive agricultural growth to meet these commitments.

The 2019 Annual Trends and Outlook Report applies a gender lens to key issues that must be addressed to fully achieve the Malabo Declaration goals. It uses a gender, agriculture, and assets framework that examines intersections between gender and (1) the context and institutions within which rural people operate; $(2)$ the natural resources that men and women depend on for agriculture, sources of vulnerability, and resilience to shocks; (3) assets; and (4) livelihood strategies. The framework recognizes that each component is gendered: men and women experience their context in different ways and the context impacts them differently; access to, ownership, and control over resources and assets can be individual or joint between men and women; and men and women use these resources to pursue different and sometimes joint livelihood opportunities.

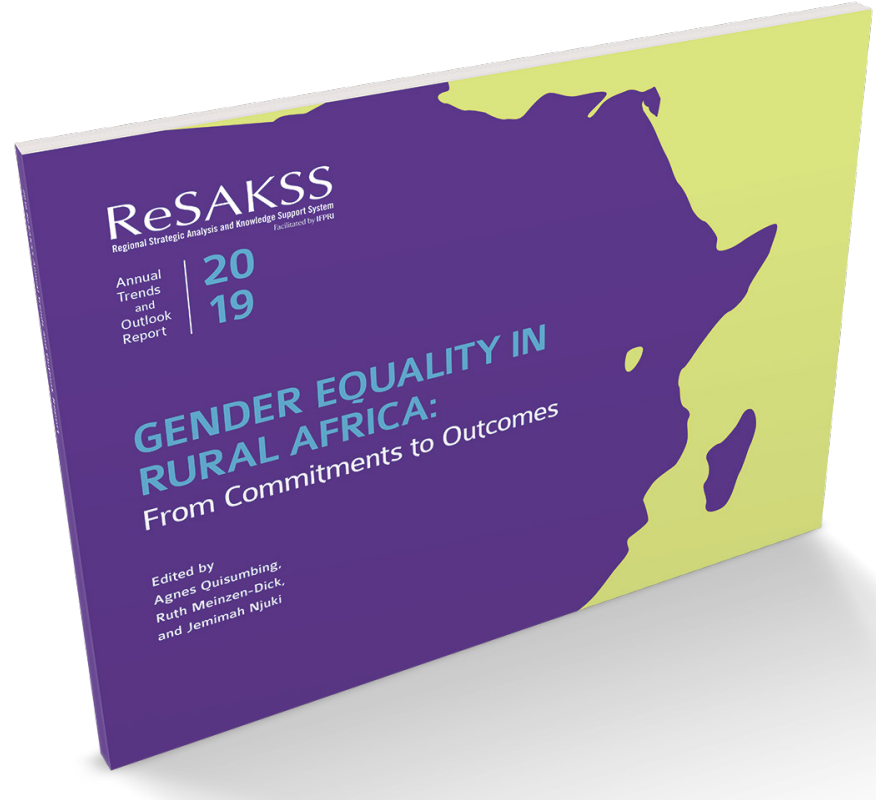

\section{Setting the context}

Gender differences arise from the socially determined relationships between men and women, and the roles that men and women play in society show similarities and differences across classes and societies. Gender norms are the set of culturally determined expectations about what it means to be a man or a woman in a particular society. These norms are increasingly recognized as important, invisible barriers undermining women's economic empowerment and preventing women from acting on opportunities and policies. Norms affect different facets of agriculture-who can own and who cannot own different resources, who can do certain things and who cannot, and who makes decisions and who cannot. This in turn affects the performance of the agriculture sector. Shifting 
social norms can be as influential as monetary incentives or policy prescriptions in influencing behavior at scale. In trying to bring about normative change, it is important to recognize that a social norms approach requires deliberate investments of time and resources, community mobilization, and engagement with community leaders and policymakers.

Gender equality and effective leadership are intertwined. Effective leadership cannot be achieved without considering inclusion of different groups in leadership. An analysis of the current trends in political governance and agriculture reveals persistent gender gaps in political representation, in agricultural research and innovation systems, and in other positions of influence in many African countries. Promoting gender equality in leadership will involve: (1) creating an enabling environment to provide a level playing field for all, especially women and youth; (2) removing systemic barriers that constrain women from taking on leadership positions; (3) collecting and documenting evidence of transformative leadership; and (4) making leaders in both research and policymaking accountable for gender equality.

\section{Assets}

Women continue to have less secure land tenure than men and, despite recent gender-friendly regulatory, administrative, and institutional land reforms in several countries, security is decreasing in some places. The ongoing social, demographic, and economic changes within Africa, coupled with emerging land markets, make it imperative to reassess customary land tenure systems and to demand that government interventions be context- and gender-specific. For example, systematic land tenure regularization programs should prioritize areas with higher and/or increasing land values, while areas with relatively land-abundant settings and lower land values may do well to leave a functional customary tenure system alone. Also, explicit provisions for women's land rights and legal literacy programs must complement land-rights protection programs to maximize gender parity outcomes.

Financial inclusion can enhance women's economic prospects and allow them to better manage their lives. The persistent gender gap in access and use of financial services and products-such as savings, credit, insurance, and transactions-is significant because people require a variety of financial products and services to fulfil their diverse daily activities. While the growth of "fintech" solutions has potential to close these gaps, barriers including women's lack of access to technologies such as mobile phones, lower literacy levels, and norms that limit women's mobility and ownership of assets can worsen the gender gap in financial inclusion. Strategies for increasing women's financial services have tended to focus on fixing women, or on making women "bankable." Instead, a more gender-transformative and sustainable approach is needed to ensure that financial institutions and the services they provide are "womenable," meaning responsive to the needs, priorities, and realities of women.

\section{Livelihoods}

Gender gaps in resources and restrictive social norms affect women's and men's livelihoods. Although women are heavily involved in agriculture and agriculture-related livelihoods across Africa, their productivity is lower than men's. Studies that have attempted to decompose the gender gap in productivity have found that, even after controlling for women's poorer access to resources, the gap in returns to resources remains. The literature points to women's more limited access to labor, to the lower value of crops grown by women, and to the fact that women are less likely to use other inputs, particularly fertilizer and machinery. Potential solutions to close the gap involve enhancing women's use of time-saving technologies; improving women's access to hired labor, particularly men's labor; supporting women in growing higher-value cash crops; increasing women's participation in agricultural producer groups; improving women's access to markets; facilitating women's use of inputs such as fertilizers; and reducing women's risk through social protection schemes and crop insurance.

While increasing productivity on the plots that women manage is important, agricultural interventions should also be designed to increase the value of output per unit of labor. This may mean farmers becoming engaged in offfarm activities with higher returns, especially in areas with poor-quality land. Finally, efforts to increase agricultural productivity need to be consistent with the goal of gender equality and women's empowerment through access to information, resources, and control over outputs. They must recognize women's contributions by involving them in programming and ensuring that women benefit from the increased productivity.

Attention to gender issues in agricultural value chain development is now widely accepted. Although the focus still largely addresses women as producers, there is growing attention to women in other parts of the chain, as processors, traders, exporters, and consumers. New research is especially needed to expand understanding of the value chains of previously neglected crops and new biofortified crops; to confirm "what works" to support women agri-entrepreneurs in starting and expanding their businesses; to identify more options for young women to engage in value chains; and to address gender-based violence in agribusiness.

Through households' production, marketing, and consumption decisions, gender affects who in the household gains nutritional and economic benefits from biofortified crops that are bred to increase micronutrient intake. Understanding the role of gender along the biofortification value chain is critical for optimizing adoption and consumption outcomes. For example, in Zambia, men generally have better access than women to information about Vitamin A maize. Gender-sensitive information dissemination can better reach women by using appropriate information channels for messaging, such as informal social networks, clinics, and radio. 
Young African women's and men's transitions to adulthood are changing because of ongoing structural and rural transformation and demographic changes. To optimize the potential of the large young population in Africathe "youth bulge"-it is important to address the unique barriers facing young women and young men. Young rural women, compared to men, are transitioning to adulthood with fewer resources, such as education and land, and their family responsibilities limit school and paid employment opportunities. Patterns of economic change may also be working against African rural youth. At higher levels of structural and rural transformation, landownership and current employment are lower, and more youth are not in employment, education, or training; these outcomes are even less favorable among young women. Programs that target marriage, fertility, and parenthood transitions usually target young women and ignore young men. Recognizing the influence of productive and reproductive roles for both rural young women and men will be important for developing sustainable livelihood opportunities.

Trade liberalization has the potential to stimulate economic growth and increase employment, however, its gendered impacts are not fully understood. How this plays out in practice is illustrated by a case study of the gendered implications of trade in Niger. Niger joined the Economic Community of West African States (ECOWAS) in 2013 and implemented its common external tariff (CET) in 2015. Analysis shows that the implementation of the CET is likely to be pro-growth and welfare-improving, thus improving employment and incomes for both men and women. However, these benefits are not equally distributed between men and women. Although women's economic activities are more exposed to regional and international trade than men's activities, women are generally less educated, less involved in associations and business networks, and have less access to productive resources. These underlying gender inequalities limit women's ability to seize the opportunities offered by greater regional trade integration. The case of Niger shows that closing the gender gap in access to productive resources, such as agricultural land and credit, is not only ethical but would also result in economic gains for women and men.

\section{Shocks and resilience}

Numerous external shocks affect men and women farmers. Resilience is the ability to draw upon a set of capacities to deal with these shocks and stressors, in a way that maintains or improves well-being outcomes such as food security or adequate nutrition. Capacities, preferences, and needs related to resilience differ between groups of people, especially when considering gendered and social differences. Programs and policies that address contextand gender-specific constraints and opportunities may be better able to build resilience by tapping into the skills and contributions of women and marginalized groups. Once local constraints are identified, approaches are available for gender-responsive resilience programming, including supporting key livelihood activities of both women and men, and promoting inclusive decision-making at the household and community levels.
Social safety nets are a core strategy in African countries and worldwide for addressing poverty and vulnerability, responding to shocks, increasing productivity, and investing in human capital. But significant evidence gaps around the effects and potential benefits of social safety nets still exist. Evidence shows that social safety nets in Africa can decrease intimate partner violence, increase psychological well-being for women, and increase economic standing, and that changes in labor force participation tend to be minimal. However, there is less evidence that social safety nets lead to women's empowerment. There is some evidence that social safety nets improve women's dietary diversity, but very limited evidence for impacts on women's food security or nutritional biomarkers. To move from promise to the successful implementation of gendertransformative social safety nets in Africa, we must invest in generation of higher quality evidence to demonstrate impacts on women's well-being.

\section{Well-being and empowerment}

Women's control over income has important implications for their own empowerment, and for reinvestment in crops and value chains that are important for women, food and nutrition security outcomes, and poverty reduction. The overall structure of agricultural production is changing, and while these shifts provide tremendous opportunities for women, if the processes of change are not managed well, women could lose out as men position themselves to serve new markets and engage in more technology-driven agricultural production methods. Increasing ownership and control over agricultural resources, including land and livestock, could have positive impacts on their control over income, but policymakers must consider how these patterns may vary across the characteristics of women themselves. The approaches that governments, development partners, and others use to transform agriculture can be designed to be better integrate women into agricultural value chains, help them maintain control over income generated, and lead to greater benefits for women and their households.

Well-designed nutrition policies can simultaneously enhance gender equality and nutrition outcomes-but they must consider men as well as women. By considering men's role in maternal and child nutrition, policies can facilitate cooperation between women and men to improve outcomes. Policies that overlook men's role miss opportunities to free up women's time to take care of their own needs and engage in productive and leisure activities-essential elements in women's empowerment. Traditional leaders should also be considered as agents of change. As custodians of culture, they can influence community members to establish more equitable practices. Overall, policymakers must partner with gender experts to strengthen gender mainstreaming at all policy levels.

The Women's Empowerment in Agriculture Index (WEAl) provides a means to measure and track changes in women's empowerment over time and across countries, regions, and population subgroups. The WEAl is an aggregate index, reported at the country or regional level, which assesses women's and men's empowerment across 5 domains and 10 
indicators, and by comparing men's and women's aggregate scores, provides a measure of gender parity. The WEAl can also be used to identify sources of disempowerment, which can then help to guide policies to close empowerment gaps. In all seven African countries for which we have data, women are more disempowered than men. Excessive workload emerges as an important contributor to disempowerment for men and women alike, with women more constrained in this indicator than men. Limited access to and control of credit likewise is a constraint for both women and men, but also with greater impact on women.

\section{Data and development targets}

An overarching need in the agriculture sector is for better gender data. Rural women and girls in Africa south of the Sahara are a key demographic to target in the aspiration to leave no one behind, but data on many aspects of their lives are lacking. Better data on rural African women and girls are needed to (1) account for all of women's work, (2) help improve women's productivity and food security and nutrition, and (3) better understand and more effectively tackle poverty. While the development sector has benefited from recent methodological advances, these have yet to fully capture the complexity of rural women's lives. And sex disaggregation of key indicators remains a major challenge. Stronger partnerships between data producers and policymakers could facilitate the development of nuanced policy to advance gender equality.

Trends assessed using the Comprehensive Africa Agriculture Development Programme (CAADP) Results Framework show that Africa has continued to make good progress on key growth targets and development outcomes. However, the rate has slowed and accelerated efforts are needed to transform Africa's agricultural sector by substantially raising productivity growth and investments in the sector. In addition, fast-tracking progress and the achievement of desired outcomes will require reinforcing the adoption of regular, comprehensive, and inclusive CAADP mutual accountability processes to facilitate evidence-based review and dialogue and to hold stakeholders accountable for their commitments to the sector.

Momentum and commitment are growing within Africa and globally toward the goals of women's empowerment and gender equality. Recognition is growing that gender gaps are imposing costs and leading to missed opportunities. The gender framework employed in this report highlights the interconnections between the themes discussed above and gender, which helps identify places for effective interventions. Nevertheless, challenging entrenched gender norms to achieve gender equality is not easy.

The chapters in this report highlight ideas for future work in research, policy, and program design and implementation. Actions to redress gender gaps are needed across the spectrum from household to community, national, and regional levels, where gender inequities persist. Creating a context in which gender equity can take root will require countries to adopt gender-equitable laws and implement programs to deliver services to women as well as men. Achieving the goals of gender equity and empowerment will also require commitment to the regional agreements such as the Malabo Declaration, which can reinforce such positive changes for society as a whole.

\title{
About ReSAKSS
}

Established in 2006 under the Comprehensive Africa Agriculture Development Programme (CAADP), the Regional Strategic Analysis and Knowledge Support System (ReSAKSS) supports efforts to promote evidence- and outcome-based policy planning and implementation. In particular, ReSAKSS provides data and related analytical and knowledge products to facilitate CAADP benchmarking, review, and mutual learning processes. The International Food Policy Research Institute (IFPRI) facilitates the overall work of ReSAKSS in partnership with the African Union Commission, the African Union Development Agency-NEPAD (AUDA-NEPAD), leading regional economic communities (RECs), and Africa-based CGIAR centers. ReSAKSS is funded by the United States Agency for International Development (USAID) and the Bill \& Melinda Gates Foundation.

ReSAKSS helps to inform the CAADP through its flagship Annual Trends and Outlook Reports (ATORs). The Africawide ATOR, which serves as the official CAADP M\&E report, tracks progress on over 30 key CAADP indicators. Each year, the ATOR presents analysis on a feature topic of strategic importance to the CAADP agenda.

\section{This synopsis is based on the peer-reviewed 2019 Annual Trends and Outlook Report-Gender Equality in Rural Africa: From Commitments to Outcomes. The full report is available for free download at https://doi.org/10.2499/9780896293649.} www.resakss.org

\section{INTERNATIONAL FOOD POLICY RESEARCH INSTITUTE}

\author{
A world free of hunger and malnutrition
}

1201 Eye St, NW, Washington, DC 20005 USA | T. +1-202-862-5600 | F. +1-202-862-5606 | Email: ifpri@cgiar.org | www.ifpri.org | www.ifpri.info DOI: https://doi.org/10.2499/9780896293656 